\title{
Benefits and Obstacles of Blockchain Applications in e-Government
}

\author{
Charalampos Alexopoulos \\ University of the Aegean \\ alexop@aegean.gr
Michalis Avgerinos Loutsaris
University of the Aegean
mloutsaris@aegean.gr

\author{
Yannis Charalabidis \\ University of the Aegean \\ yannisx@aegean.gr
}

\author{
Aggeliki Androutsopoulou \\ University of the Aegean \\ ag.andr@aegean.gr \\ Zoi Lachana \\ University of the Aegean \\ zoi@aegean.gr
}

\begin{abstract}
Nowadays, Blockchain Technologies (BCT) could be characterized as one of the most promising trends. We are currently witnessing a plethora of implementations basically in the economic sector with the creation of cryptocurrencies. The majority of researchers and practitioners argues that many benefits could be derived from the use of this innovative technology with the most significant one being the improved sense of trust to BCT applications. At the same time governments pursue amplified trust from their citizens and BCT is gaining momentum since it addresses this of utmost importance problem based on its unique characteristics. More and more governments realize the advances of this technology and participate in pilot applications in different vertical governmental sectors. Even though there are several implementations in the Government sector, there is no comprehensive study towards the analysis of the major characteristics of these developments. This paper moves towards the fulfilment of this gap conducting a thorough analysis of e-Government pilot applications of BCT in a European level. Furthermore, this study discusses the key benefits and main barriers coming from the application of this technology in different domains with BCT experts.
\end{abstract}

\section{Introduction}

Government 3.0 [38] refers to the use of disruptive ICTs such as big data, blockchain technologies and artificial intelligence technologies in combination with established ICTs such as distributed technologies for data storage and service delivery and the wisdom of crowd (crowd-sourcing and co-creation) towards datadriven and evidence-based decision and policy making [29][43].

Previous research mapping the disruptive technologies against their transformative capacity within the public sector, conducted in the context of the Sonnets Project [42], has indicated that currently the most hyped technology is BCT. BCT consists the technology behind Bitcoin, both introduced and implemented by Nakamoto [28]. Hou [20] defines BCT as "...a distributed ledger that maintains a continually growing list of publicly accessible records cryptographically secured from tampering and revision".

Zhang [52] compares BCT to a creation of a persistent, immutable, and ever-growing public ledger that can be updated to represent the latest state of it. It was originally used to record historical transactions of encrypted digital currencies, such as bitcoin [54] and smart contract platforms like Ethereum. However, BCT is much more than enablers of crypto-currencies: a BCT can be thought of as a distributed record of any type of transactions between parties, where transactions are validated and recorded in chronological order (in a sequence of "blocks" - hence the name) by a decentralized network of peers [3], without need for a central/trusted/third party. The disruptive potential of BCT stems from its capability to facilitate peer-to-peer transactions without intermediaries, while at the same time validating and keeping a permanent public record of all transactions. As Zheng et. al [53] mentioned, "Although Bitcoin is the most famous application of blockchain, blockchain can be applied into diverse applications far beyond cryptocurrencies".

BCT has also a great potential for use in the public sector. Since any transaction can be completed without the use of any intermediary [18], Blockchain is a promising solution for a variety of services [30] such as smart contracts [1], public services [6] as Blockchain can improve the security of "core government data" [32], Internet of Things (IoT) [55], reputation systems [27] and security services [33]. Blockchain is cited as a promising technology especially for public services [26] that could influence society or even businesses [51]. By using a P2P network BCT is considered as the best solution so far 
for transactions between system's actors (called nodes) while storage of these transactions in a distributed way is a fact [5]. One of the most important processes is the consensus mechanism an agreement by a selected number of nodes for the next block to be added [48]. BCT constitutes a safe technology since any transaction in which taking place can be stored and cannot be removed enabling all nodes to track the history. Distributed ledger is the usage of different nodes in order to store transaction information [35]. Digital signature is a combination of private key and transaction's data (for example owner of the assets). Public keys and digital signatures are being used in order for a safe transaction to be completed [50].

While applications of BCT in the private sector are exaggerating, high interest has emerged as well, in its utilisation in governance. A recent survey conducted by IBM [21] and the Economic Intelligence Unit, that 7 out of 10 Government executives predict BCT will significantly disrupt the area of contract management, while $14 \%$ of Government organizations expect to have BCT in production and at scale in 2017. The same study indicates that 9 out of 10 Government organizations plan to invest in BCT for use in financial transaction management, asset management, contract management and regulatory compliance by 2018 . Market sectors that already indicate compelling applications of BCT include finance, real estate, voting systems, healthcare and shipping. The innovation potential in the above sectors emerges from the merits of blockchain on security, privacy, transparency enhancement and fraud prevention. Furthermore, BCT keeps sensitive information (personal, business etc) secured and private, allowing an unmediated process of a transparent and indestructible activity.

As it has been stated in a number of recent studies [14], Distributed Ledger Technologies (DLT's) can also significantly contribute in making the public sector a faster, more open, trusted party, while unlocking the potential of citizens and enterprises, towards a more collaborative, yet managed, ecosystem of services. The ability to record transactions on distributed ledgers offers new approaches for governments to address societal, business or public sector needs as faster and transparent access to public sector services, prevent fraud and establish trust. BCT implementations are largely technology driven and often various combinations of technologies are needed to make the BCT architecture fit for e-Government applications [14]. However, since the field is still in its infancy, a series of challenges exist, which call for further investigation. Therefore, it is necessary to analyse BCT from various perspectives, in order to gain a better understanding of its potential, benefits as well as factors that determine their adoption in the public sector. Our paper makes a contribution towards this direction. On the one hand it reviews existing literatures on the e-Government field, on the other it presents the current landscape of BCT implementations in the public sector. Hence, the aim of this study of the literature is to identify benefits and barriers for the application of BCT in Government and shape the directions of future research in the Government 3.0 field related to that.

This paper consists of seven sections. In the following section 2 the methodology underlying our research is presented. Section 3,4,5 illustrate the results of the literature, the analysis of the existing implementation of BTC in the public sector and the workshop conducted. Section 6 summarizes the benefits and challenges of BTC. In the final section 7 the conclusions are summarized, and future research directions are proposed.

\section{Methodology}

This chapter presents the methodological approach of our study in order to complete a review of the current landscape of BCT. Based on documentary analysis we seek to produce evidences for substantiating our research claims.

Documentary analysis could be defined as "a systematic procedure for reviewing or evaluating documents-both printed and electronic (computerbased and internet-transmitted) material" [54]. We used documentary analysis in order to categorize, investigate and identify written documents from the conducted literature review, whether in the private or public domain (personal papers, commercial records, or state archives, communications or legislation [37, p.60]. Given that we tapped both online and offline records to investigate the nature.

We first conduct a literature review that enabled us to assemble the basic types and characteristics of BCT, as well as the types of benefits and barriers that have been identified until now. In particular, the research began by searching for relevant publications in the EGRL database using the following keywords: "blockchain government", "blockchain public sector", "blockchain benefits", "blockchain barriers", "blockchain challenges", "blockchain public services". Then it continued with a careful examination of four bibliographic databases, Google Scholar, Scopus, IEEE Xplore and Web of Science using the same keywords.

The next step of our methodology consists of the identification of running projects relevant to egovernment. Combined with desk research we analysed each project by its domain of application, type of BCT, partner that undertook implementation 
and the scope of the application (local, national etc.). In this step we reviewed public and private sector documents about the results and the aims of the identified projects.

The final step of our methodology includes the organisation of semi-structured interviews with 6 experts from the industry (3), the academia (2) and the public sector (1). Interviews serve as the primary means of data collection in the qualitative research [12]. For that reason, a workshop has been organised during the kick-off meeting of the Hellenic Blockchain Hub $(\mathrm{HBH})$, where we had the opportunity to discuss with blockchain experts from Greece about the importance and prospects as well as the challenges of BCT in Government in order to validate our findings and identify missing parts. The workshop lasted three hours where a set of 10 questions were used to motivate the discussion in Greek language. The results of these steps (i.e. literature, applications review and workshop) are reported in the following sections and finally. Then in section 6 the results have been merged and analysed. Section 4 on potential benefits and challenges of the technology is a merge of literature review and interviews results. Section 5 presents the projects types and countries of implementation and it is the result of the second step of the methodology. The discussion and conclusions sections are derived from all the three steps of the methodology.

\section{Literature Review}

Different scholars provide literature reviews of the use of BCT in government. Ølnes [34] shows that the majority of articles dealing with BCT focus primarily on the technology behind bitcoin and until 2015 there are few publications relative to BCT in Government in the literature databases (including bitcoin, crypto currency technology, eGovernment, electronic Government, e-Government e.tc). The author suggests that in order to be a potential valuable technology for use in public sector BCT needs to be more than a payment solution.

Generally, as OPSI [36] mentioned BCT has three goals to be achieved. These goals are: (a) Reduce or Eliminate the need of a central authority, (b) Eliminate central points of failure and (c) Enable trust among people who don't know each other to directly conduct transactions.

As it was noted BCT is often used as a solution for the improvement of public services. Recent case studies include BCT for digital payments [23], providing academic certificates stored on the BCT at the University of Nicosia [30], a sovereign government

- backed identity credential as a pilot (e-ID card) in Dutch [2] and healthcare, pensions, Government performance, food safety and Government divisions, all of which have close relationships with individuals' livelihood in China [19]. Furthermore, Dubai wants all government documentation to be transacted digitally by using blockchain. According to the Dubai Blockchain strategy, Government believes that adopting blockchain technology will save 5.5 billion dirham [11]. Also, NCSL [31] estimates that 10 percent of global GDP will be stored on BCT by 2027.

Another stream of literature shows that there are more than one categories/types for current BCT systems. Buterin [9] and Zheng et al.[53] distinguish three types which are (1)public BCT, (2)private BCT and (3)consortium BCT while Ølnes et al [35] stated that BCT systems can be viewed into two basic types (1) private BCT or (2) public BC including their subcategories which are either open/permissionless or closed/permissioned. The two types of ledger's condition, i.e. private/closed or public/open determine who has access to copies of the ledger while the characterization of permissioned or permissionless determines who maintains the ledger.

Consensus determination is the mechanism which validates the next block. In public permissionless BCT each node can participate in the process, while in public permissioned BCT and in private permissionless BCT a selected set of nodes. Private permissioned BCT is fully controlled by the owner. Read permission determinize whether stored transactions are restricted or can be viewed and immutability determinizes the possibility of the BCT to be tampered. Efficiency is the key which shows the velocity of any transaction. The number of participant nodes defines the centralization of a chain, less nodes means centralized or partial centralized. Finally, consensus process specifies permissions among the chain.

\section{Landscaping BCT Applications in e- Government}

The continuously growing number of BCT initiatives that are being adopted in the public sector by various states is a strong indicator of the current trend advocating the utilization of key BCT capabilities in the respective services. The adoption of BCT by the Estonian government is the more advanced example of the exploitation of the technology in the public sector. Specifically, the Estonian e-Government approach is built around a service-rich ecosystem consisting of approximately 3000 services including identity management, tax collection, voting, etc. Similar initiatives have been also implemented by other states although at a narrower scale in terms of number of services- such as the United Kingdom, where services 
like welfare payments are powered by BCT. The full list of the identified BCT applications in EU is presented in the Appendix.

In general, the use of BCT in the public sector is still limited to few relevant cases. The most relevant cases are reported in the table of the APPENDIX that presents a short list of BCT solutions for the public sector. BCT represent a core segment of technology innovations that create significant opportunities for a major and disruptive refresh of a wide spectrum of infrastructure and applications. The analysis of these BCT applications results in the following observations:

- The applications have covered a lot of domains: health records, identity management, land registry, document exchange and academic certificates.

- The majority of BCT implementations in the EU area results from partnerships with private companies, undertaking the role of technology providers that implement $\mathrm{BCT}$ based solution to governments.

- The innovators and leading countries in the domain of BCT running an e-government project are located in the Northern and more specifically in the North-western Europe (Estonia, Switzerland, Finland, United Kingdom, Luxembourg, Norway, Sweden), while 2 countries are located in the Southern and Southwestern Europe (Malta, Spain).

- In terms of specific countries, Estonia has the lead with 3 production level large scale implementations, UK is the second position with 1 production level large scale implementation and 2 ongoing proof of concepts and Switzerland holds the third place with 1 production level large scale implementation and 1 ongoing proof of concept.

- In terms of BCT types that are used in the ongoing and completed projects, the private BCT type holds $70 \%$. $80 \%$ of the solutions are applied nationally, while two are applied at municipal and one at organizational levels.

- The applications and/or case studies could be categorised in three different groups according to their Technology Readiness Level: (a) large-scale implementations (50\%) with $43 \%$ of them being at production level, (b) pilot applications $(21 \%)$ most of them completed and (c) proof of concept (29\%) with most of them ongoing.

- The applications and/or case studies utilise both public and private BCT regardless of their scope. For example, identity management and land registry projects utilise both public and private ones. Projects dealing with health records utilising private BCT implementation.

- There are different levels of initiatives extension. They are applied at the organisational, municipal and national level. The majority of the case studies have been implemented at national level. There is no correlation between the level of extension and the type of application according to their TRL level. Some large-scale implementations applied to the national level while other national implementations have developed proof of concept. This probably depends on the experience of the staff involved and the orientation of national governments towards the adoption of innovation (i.e. how much they trust or are convinced about the benefits of the new BCT).

However, the conflict between GDPR [15] and $\mathrm{BCT}$ raises important legal considerations for public and private sector seeking to implement blockchain solutions that involve personal data [24]. Data immutability [39], a key feature of the BCT is against the new requirements of the GDPR especially the erasure right [41], which demands the erase of the personal data of individuals when they request to be "forgotten" [24]. Another issue is the complicating GDPR's definition of "personal data" which defines them as any information relating to a natural person, either identified or even identifiable, who can be directly or indirectly identified in particular by reference to an identifier such as a name or an identification number [24][39][41]. Some experts [39][24] believe that a cryptocurrency wallet address can be considered as personal data due to GDPR is it is publicly available.

\section{Workshop findings}

Workshop validated the insights that come out of the literature review. Most of interviewed experts agree on the fact that Blockchain is a promising technology that will frame Government 3.0 but lacks evaluation results as well as requirements specification in the applied domains. One expert from the public sector stated: "...the way forward is to apply and evaluate". Government 3.0 is about data-intensive policy making in which the BCT offers the great advantage of trustworthy data for analysis and decision support. Another expert from industry stated: "... all benefits coming from the utilisation of BCT or DLT in eGovernment will alternate the way public services are offered". Another expert from academia stated: "We are a step closer to the realisation of the fifth stage of e-Government - personalisation and proactive government", since the information will not be circulated between different information systems through web services but it will be always there for use. 
The discussion with the experts unveils two major issues about BCT use and future prospects: Data exchange through BCT could not be applied in all systems. According to General Data Protection Regulation (GDPR) [15], the right to be forgotten, also known as data erasure, "...entitles the data subject to have the data controller erase his/her personal data, cease further dissemination of the data, and potentially have third parties halt processing of the data. The conditions for erasure, as outlined in article 17, include the data no longer being relevant to original purposes for processing, or a data subjects withdrawing consent. It should also be noted that this right requires controllers to compare the subjects' rights to "the public interest in the availability of the data" when considering such requests.". Since this right should be applied in certain occasions dealing with sensitive information of a human being such as health history (a person might need at some point to erase his/her information from his/her health record), it constitutes a great barrier in BCT application. It is obvious that each system should carefully evaluate its transition to BCT. Most of the cases in Government though does not apply to this regulation.

\section{Results and Discussion}

Considering BCT's great potential of use, it is clear to governments (including organizations and policy makers) that by including this technology into their strategies they could gain as a result a significant advantage in a fast change eco-system. A resolution on virtual currencies (VCs) and BCT (DLT) is passed by the EU Parliament on 26th of May 2016 [17]. Moreover, it has approved a task force dedicated to cryptocurrencies and BCT [23], and the summer of 2017 opened a call for proposals to set-up a European Expertise Hub on BCT and Distributed Ledger Technologies [16]. Among the rest of the EU initiatives, the European Commission is seeking submissions for a new BCT development contest with a 5M Euros top prize [10] and is launching a study aimed to assess the feasibility and potential of an EUwide infrastructure [45]. Similarly, the US Congress has launched the so-called Congressional BCT Caucus on 26 September 2016. According to Rep. Jared Polis (D-Colo.) [40].

\subsection{Benefits for Public Services}

Hou [20] reveals that BCT can bring many benefits including improvements in the quality and quantity of Government services by the simplification of most Government processes, such as bureaucratic processes,
Government information with greater transparency, open and accessible Government information to citizens and businesses including information-sharing across different organizations development, and even assistance in building an individual credit system. Citizens and businesses can easily gain access to government's information thus government's credibility could be improved by using BCT platforms [13] and data safety [19] in every transmission could also be part on every transaction among any authorized party including participant's anonymity by the usage of encryption keys [7]. Moreover, storing any secured information using BCT it consists a profitable solution for public services. Thus, offered Government services could be personalized and borderless transforming society into a more collaborative one [46] [4]. Table 1 presents the recognized benefits from the utilization of BCT in public services.

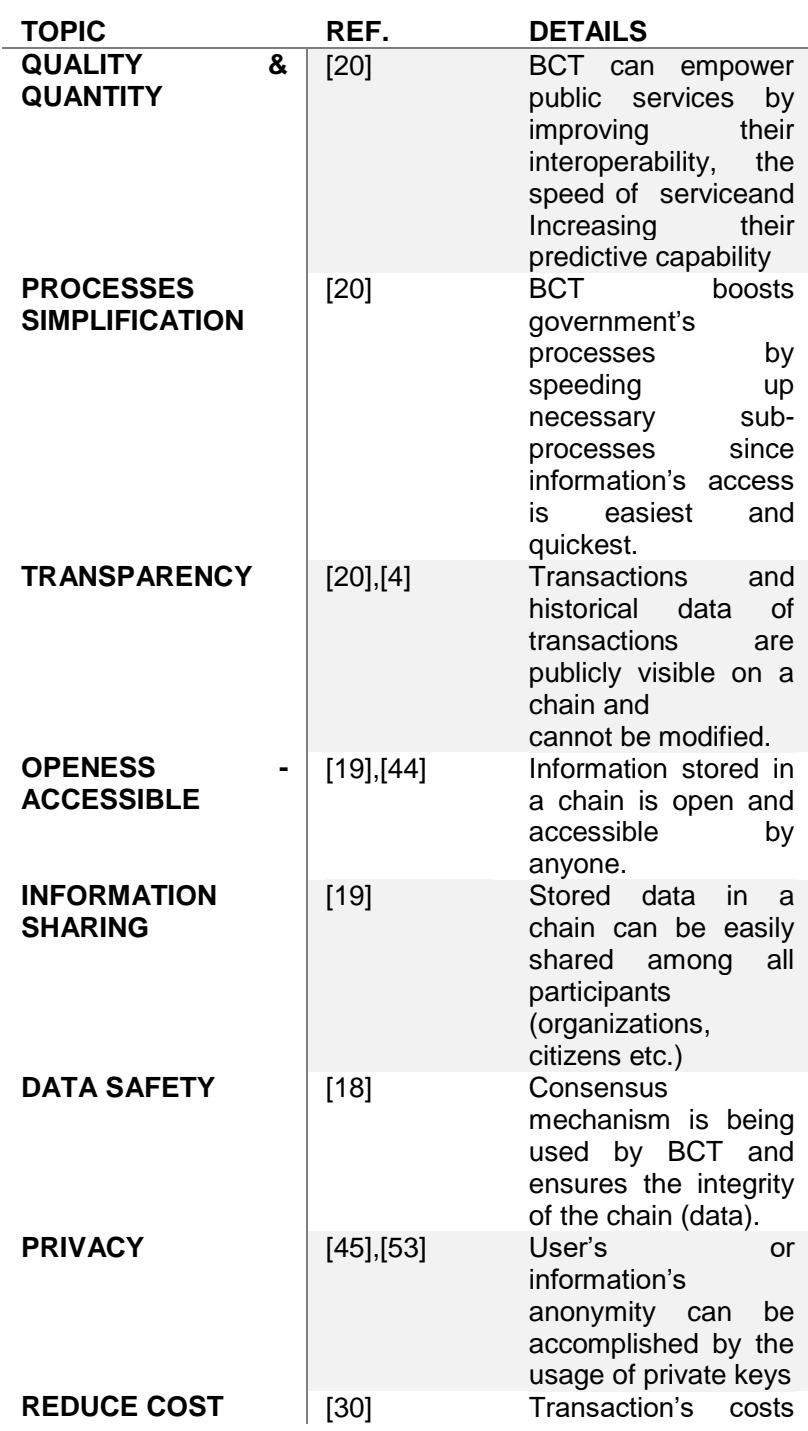




\begin{tabular}{|c|c|c|}
\hline & & $\begin{array}{l}\text { can be reduced since } \\
\text { by using BCT the } \\
\text { need for third parties } \\
\text { is being removed. }\end{array}$ \\
\hline $\begin{array}{l}\text { GOVERNMENT } \\
\text { CREDIBILITY }\end{array}$ & {$[14],[19]$} & $\begin{array}{l}\text { BCT-based platforms } \\
\text { can be used to give } \\
\text { citizens access to } \\
\text { reliable } \\
\text { governmental } \\
\text { information } \\
\text { increasing citizens' } \\
\text { trust to governments. }\end{array}$ \\
\hline STANDARDIZATION & $\begin{array}{l}\text { HBH } \\
\text { WORKSHOP }\end{array}$ & $\begin{array}{l}\text { There are eight ISO } \\
\text { standards under } \\
\text { development for BCT }\end{array}$ \\
\hline FLEXIBILITY & $\begin{array}{l}\text { HBH } \\
\text { WORKSHOP }\end{array}$ & $\begin{array}{l}\text { BCT can be used in } \\
\text { several ways in order } \\
\text { to improve public } \\
\text { services. }\end{array}$ \\
\hline
\end{tabular}

Table 1. Potential Benefits of BCT usage by governments

\subsection{Challenges of using BCT in Government}

Concurrently, the application of the BCT to the domain of e-Government is associated with some challenges [50] as listed on Table 2.

\begin{tabular}{|c|c|c|}
\hline TOPIC & REF. & DETAILS \\
\hline SCALABILITY & {$[50]$} & $\begin{array}{l}\text { Since only few } \\
\text { transactions per second } \\
\text { can be processed, } \\
\text { transactions might be } \\
\text { delayed. }\end{array}$ \\
\hline $\begin{array}{l}\text { PRIVACY } \\
\text { LEAKAGE }\end{array}$ & {$[50]$} & $\begin{array}{l}\text { Public keys of any } \\
\text { transaction are being } \\
\text { visible, so safety } \\
\text { challenges may be } \\
\text { detected }\end{array}$ \\
\hline SELFISH MINING & {$[21],[50]$} & $\begin{array}{l}\text { Selfish miners may try } \\
\text { to acquire nodes' } \\
\text { computing power in } \\
\text { order to reverse } \\
\text { transactions. }\end{array}$ \\
\hline $\begin{array}{l}\text { TRUST OF THE } \\
\text { TECHNOLOGY }\end{array}$ & [19] & $\begin{array}{l}\text { A blind trust which relies } \\
\text { exclusive on the BC's } \\
\text { technology may include } \\
\text { risks }\end{array}$ \\
\hline $\begin{array}{l}\text { LEGALLY } \\
\text { BINDING }\end{array}$ & [44] & $\begin{array}{l}\text { Although chain is } \\
\text { accessible by any node, } \\
\text { information may be } \\
\text { invalid in other nation } \\
\text { states. }\end{array}$ \\
\hline $\begin{array}{l}\text { APPLICABILITY } \\
\text { IN TERMS OF } \\
\text { GDPR }\end{array}$ & $\begin{array}{l}\text { HBH } \\
\text { WORKSHOP }\end{array}$ & $\begin{array}{l}\text { GPDR's goal is } \\
\text { opposite effective in } \\
\text { some cases compared } \\
\text { with BCT's especially in } \\
\text { the domain of personal } \\
\text { data. }\end{array}$ \\
\hline
\end{tabular}

Table 2. Potential challenges of BCT
Scalability consists an important challenge problem, since only seven transactions per second can be processed. If we consider BCT as a payment solution used by Government with a requirement of processing millions of transactions, many of these transactions might be delayed. Furthermore, while BCT uses public keys publicly visible of any transaction there might be safety challenges including information leakage [53]. Another challenge reported by Zheng et al.[53] is Selfish Mining. While selfish miners trying to hack the chain, not only nodes with more than a half $(51 \%+)$ computing power can reverse a transaction but it is shown [22] that also around the half computing power is dangerous.

Another challenge which is faced by the usage of $\mathrm{BCT}$ is the impression that only the trust of the technology is enough for a system to be safe. As Hou [20] mentioned "At present, a danger actually comes not from system vulnerabilities, but from blind trust in the blockchain on the part of blockchain developers, lawmakers, law enforcement and the general public. This trust relies exclusively on the technology, rather than management, to make sure the system is trusted and the records in the system are reliable".

Alternative, authentication can be offered to be valid in one country for instance e-IDs, but they are not necessarily legally binding in any other nation state. Moreover, as Sullivan [44] mentioned "...there is the risk that identity information authenticated on the Blockchain but which is otherwise invalid may find its way into traditional channels to enable creation of new, false identities, which could then be used to hide one's real identity".

\section{Conclusions and further research directions}

This study has conducted a review towards the identification of benefits and obstacles towards the adoption of the BCT innovative technology in the public sector. Our findings indicate that $\mathrm{BCT}$ as an enabling array of technologies that can contribute to the openness and transparency of services in the public sector. This technology has been analyzed as a prominent component of the next generation of egovernment, namely, Government 3.0. According to the applications and benefits identified, blockchainbased technologies can be incorporated in several public services and enhance transparency and trust in governments. Newest application scenarios could allow even immigrants' new identities and health records that could never been falsified. At the level of public administrations, record keeping constitutes the most widely-used application area of BCT due to a 
series of advantageous technical properties related to the creation/verification of records, namely, speed, security and transparency. BCT is capable of underpinning many innovations such as the Internet of Things, as well as disrupting radically its own. Many technologies have great potential for use but without including the service provision. Instead, BCT is a promising technology and by having a great potential, can be used in public sector. Despite Blockchain consists a transformative technology and not a political one, its political implications are significant, considering technology's affords which can reconfigure ultimately broader socio-political relationships such as legal, institutional even economic.

However, considering all BCT's benefits and challenges, it is important to understand whether the use of a technology such BCT is important in the domain of e- Government and if so in which sectors. Careful consideration on the use of BCT should be given in the cases the GDPR right to be forgotten is applied. Even bank records could be deleted after five years. Moreover, all the identified benefits and obstacles should be proven and addressed through impact analyses and thorough examination of current and future applications. Future studies have to answer a lot of research questions to confirm the importance of using this emerging technology by governments. Among the many research questions are which is the value of adopting BCT by governments? To what extend citizens' trust will be influenced by the adoption of this technology? Does BCT constitute the start of a new internet era? To what extend the use of this technology will help governments to struggle against fraud? Which is the effect of enabling and supporting (including Government's existing infrastructures) this technology? Should public sector use a separate sidechain and if so, what would be the major threats to such a strategy? What are the important factors determining the adoption of Bitcoin technology in public sector? How can BCTs be beneficial for governments and citizens at any mentioned level? According to the answers, governments could identify the impact of BCT adoption by public services and how public sector should approach the BCT.

\section{References}

[1] Ahmed Kosba, Andrew Miller, Elaine Shi, Zikai Wen, and Charalampos Papamanthou. Hawk: The blockchain model of cryptgraphy and privacy-preserving smart contracts. In Proceedings of IEEE Symposium on Security and Privacy (SP), pages 839-858, San Jose, CA, USA, 2016.

[2] Alexandre A. (2018). R3 Partners With Dutch Tech Company to Pilot Blockchain-Based Digital IDs. https://cointelegraph.com/news/r3-partners-with-dutch-techcompany-to-pilot-blockchain-based-digital-ids

[3] Antonopoulos, A.M. Mastering Bitcoin: Unlocking Digital Crypto-Currencies. Sebastopol, CA: O'Reilly Media, 2014.

[4] Atzori, M. (2015). Blockchain technology and decentralized governance: Is the state still necessary?.

[5] Back, A., Corallo, M., Dashjr, L., Friedenbach, M., Maxwell, G., Miller, A., ... Wuille, P. (2014). Enabling blockchain innovations with pegged sidechains. Open science review (https://www.blockstream.ca/sidechains.pdf ).

[6] Benjamin W. Akins, Jennifer L. Chapman, and Jason M. Gordon. A whole new world: Income tax considerations of the bitcoin economy. 2013.

[7] Böhme, Rainer, Nicolas Christin, Benjamin Edelman, and Tyler Moore. 2015. "Bitcoin: Economics, Technology, and Governance." Journal of Economic Perspectives, 29 (2): 21338.

[8] Bowen, G.A. (2009), "Documentary analysis as a qualitative research method", Qualitative Research Journal, Vol. 9 No. 2, pp. 27-40.

[9] Buterin, V. (2014). Ethereum White Paper: A nextgeneration smart contract and decentralized application platform. Ethereum white paper

[10] De, Nikhilesh. (2017, November 10). EU Officials Reveal $€ 5$ Million 'Blockchains for Social Good' Contest. Retrieved from https://www.coindesk.com/eu-officialsreveal-e5million-blockchains-social-good-contest/amp/

[11] Dubai Blockchain Strategy (2018) https://smartdubai.ae/en/Initiatives/Pages/DubaiBlockchainSt rategy.aspx

[12] Denzin, N.K. and Lincoln, Y.S. (1998), Collecting and Interpreting Qualitative Materials, Sage, Thousand Oaks, CA.

[13] E Zhang, "Antshares Whitepaper1.0," Available at: https://github.com/AntShares/AntShares/wiki/Whitepaper1.0. Accessed on 1 March 2018.

[14] Engelenburg, S.v., Janssen, M., \& Klievink, B. (2017). Design of a software architecture supporting businesstogovernment information sharing to improve public safety and security: Combining business rules, events and blockchain technology. Journal of Intelligent Information Systems. (forthcoming)

[15] EUGDPR (2017) The EU General Data Protection Regulation (GDPR)

[16] European Commission, EU Blockchain Observatory and Forum. (n.d.). July 2017 
[17] European Parliament, 2.50.04.02 Electronic money and payments, cross-border credit transfers, March 2016

[18] Foroglou, G., \& Tsilidou, A. L. (2015). Further applications of the blockchain. In 12th Student Conference on Managerial Science and Technology.

[19] Gervais, A., Karame, G. O., Wüst, K., Glykantzis, V., Ritzdorf, H., \& Capkun, S. (2016). On the security and performance of proof of work blockchains. Proceedings of the 2016 ACM SIGSAC conference on computer and communications security (pp. 3-16). ACM

[20] Hou H. (2017, July). The Application of Blockchain Technology in E-Government in China. In Computer Communication and Networks (ICCCN), 2017 26th International Conference on (pp. 1-4). IEEE.

[21] IBM (2017). Four Ways Blockchain Could Aid Governments.

https://www.ibm.com/blogs/think/2017/01/four-ways-

forblockchain/

[22] Ittay Eyal and Emin Gün Sirer. Majority is not enough: Bitcoin mining is vulnerable. In Proceedings of International Conference on Financial Cryptography and Data Security, pages 436-454, Berlin, Heidelberg, 2014.

[23] Kastelein, R. (2016, May 30). EU Parliament Approves Blockchain and Cryptocurrency Task Force. Retrieved from http://www.the-blockchain.com/2016/05/30/eu-

parliamentapproves-blockchain-and-cryptocurrency-taskforce/

[24] Kramer, N. (2018, April 17). Blockchain, Personal Data and the GDPR Right to be Forgotten. Retrieved from https://www.blockchainandthelaw.com/2018/04/blockchainpersonal-data-and-the-gdpr-right-to-be-forgotten/ GDPR, International, Privacy, Regulation

[25] Luther, W. J. (2016). Bitcoin and the future of digital payments. The Independent Review, 20(3), 397-404.

[26] Mike Sharples and John Domingue. The blockchain and kudos: A distributed system for educational record, reputation and reward. In Proceedings of 11th European Conference on Technology Enhanced Learning (EC-TEL 2015), pages 490-496, Lyon, France, 2015.

[27] Morabito, V. (2017). Blockchain Governance. In Business Innovation Through Blockchain (pp. 41-59). Springer, Cham.

[28] Nakamoto, S. (2008). Bitcoin: A peer-to-peer electronic cash system.

[29] Nam, T. Challenges and Concerns of Open Government: A Case of Government 3.0 in Korea. Soc. Sci. Comput. Rev. 2015, 33, 556-570.
[30] Narayanan, A., Bonneau, J., Felten, E., Miller, A., \& Goldfeder, S. (2016). Bitcoin and Cryptocurrency Technologies: A Comprehensive Introduction. Princeton University Press.

[31] NCSL (2017). Blockchain Technology: An Emerging Public Policy Issue. LegisBrief (vol. 25 no. 44) http://www.ncsl.org/documents/legisbriefs/2017/lb_2544.pdf

[32] Nielsen, M. M., \& Krimmer, R. (2015, May). Reuse of Data for Personal and Proactive Service: An Opportunity Not Yet Utilised. In CeDEM15: Conference for E-Democracy and Open Government (Vol. 273). MV-Verlag.

[33] Noyes, C. (2016). Bitav: Fast anti-malware by distributed blockchain consensus and feedforward scanning. arXiv preprint arXiv:1601.01405.

[34] Ølnes, S. (2016, September). Beyond bitcoin enabling smart government using blockchain technology. In International Conference on Electronic Government and the Information Systems Perspective (pp. 253-264). Springer, Cham. https://doi.org/10.1007/978-3-319-44421-5_20

[35] Ølnes, S., Ubacht, J., \& Janssen, M. (2017). Blockchain in government: Benefits and implications of distributed ledger technology for information sharing. Government Information Quarterly, 34(3), 355-364.

[36] OPSI (2018). Blockchain and its Use in the Public Sector. https://oecd-opsi.org/wpcontent/uploads/2018/06/Blockchains-Unchained-Slides.pdf

[37] Payne, G. and Payne, J. (2004), Key Concepts in Social Research, Sage, London.

[38] Pereira, G., Charalabidis, Y., Alexopoulos, C., Mureddu, F., Paryced, P., Ronzhyn, A., Flak, L. and Wimmer, M. A. (2018). Scientific foundations training and entrepreneurship activities in the domain of ICT-enabled Governance. In Proceedings of DG.O 2018, Delft, Netherlands, May2018.

[39] Pilkington, M. (2016). 11 Blockchain technology: principles and applications. Research handbook on digital transformations, 225.

[40] Polis, J. (2016, September 26). Polis launches Congressional Blockchain Caucus. Retrieved from http://polis.house.gov/news/documentsingle.aspx?DocumentI $\mathrm{D}=398230$

[41] Safari, B. A. (2016). Intangible Privacy Rights: How Europe's GDPR Will Set a New Global Standard for Personal Data Protection. Seton Hall L. Rev., 47, 809.

[42] SONNETS (2015). Policy Maker Content - Related Recommendation.

http://www.sonnetsproject.eu/sites/default/files/sonnets/publi c/contentfiles/article/Policy\%20Maker_Contentrelated\%20R ecommendation\%205.pdf 
[43] Song, I. K. Emerging Internet Technology \& Service toward Government 3.0. KSII Trans. Internet Inf. Syst. 2014, $8,540-546$

[44] Sullivan, C., \& Burger, E. (2017). E-residency and blockchain. Computer Law \& Security Review, 33(4)

[45] Sundararajan, Sujha. (2017, November 13). European Commission to Assess Potential of EU-Wide Blockchain Infrastructure. Retrieved from https://www.coindesk.com/european-commission-toassesspotential-of-eu-wide-blockchain-infrastructure/amp/

[46] Swan, M. (2015). Blockchain: Blueprint for a new economy. " O'Reilly Media, Inc.".

[47] Tapscott, D., \& Tapscott, A. (2016). The impact of blockchain goes beyond financial services. Harvard Business Review

[48] Van Valkenburgh, P., Dietz, J., De Filippi, P., Shadab, H., Xethalis, G. \& Bollier, D. 2015. Distributed collaborative organisations: Distributed networks and regulatory frameworks. Harvard Working Paper. [Accessed 2016].

[49] Vitalik Buterin. On public and private blockchains. https://blog.ethereum.org/2015/08/07/on-public-andprivateblockchains, 2015.
[50] Warburg, B. (2016). How the blockchain will radically transform the economy. TEDSummitTED Talk (June 2016. Retrieved from https://www.ted.com/talks/bettina_warburg_how_the_blockc hain_will_radically_transform_the_economy?language=en).

[51] Webb, A. (2015). 8 tech trends to watch in 2016. Harvard business review, December 8th 2015 (Retrieved from https://hbr.org/2015/12/8-tech-trends-to-watch-in2016).

[52] Zhang, F., Cecchetti, E., Croman, K., Juels, A., \& Shi, E. (2016, October). Town crier: An authenticated data feed for smart contracts. In Proceedings of the 2016 aCM sIGSAC conference on computer and communications security (pp. 270-282). ACM.

[53] Zheng, Z., Xie, S., Dai, H. N., \& Wang, H. (2016). Blockchain challenges and opportunities: A survey. Work Pap.-2016.

[54] Zhu H., Zhou Z. Z. (2016, February) "Analysis and outlook of applications of blockchain technology to equity crowdfunding in China," Financial Innovation, p.29.

[55] Zyskind, G., \& Nathan, O. (2015). Decentralizing privacy: Using blockchain to protect personal data. IEEE security and privacy workshops (SPW2015) (pp. 180-184).

\section{APPENDIX: Examined Blockchain Initiatives}

\begin{tabular}{|c|c|c|c|c|c|c|}
\hline $\begin{array}{l}\text { Implementation } \\
\text { Partners }\end{array}$ & Government & $\begin{array}{c}\text { Application } \\
\text { Level }\end{array}$ & $\begin{array}{l}\text { BCT } \\
\text { Type }\end{array}$ & $\begin{array}{l}\text { Technology } \\
\text { Readiness }\end{array}$ & Domain & About \\
\hline Blockcerts $^{1}$ & Malta & National & Public & Ongoing Pilot & $\begin{array}{l}\text { Academic } \\
\text { Certificates }\end{array}$ & $\begin{array}{l}\text { Blockcerts is an open standard for } \\
\text { creating, issuing, viewing, and } \\
\text { verifying blockchain } \\
\text { based certificates. }\end{array}$ \\
\hline Uport $^{2}$ & Switzerland & Municipal & Public & $\begin{array}{l}\text { Ongoing } \\
\text { Large Scale } \\
\text { Impl. }\end{array}$ & $\begin{array}{c}\text { Identity } \\
\text { Management }\end{array}$ & $\begin{array}{l}\text { uPort is a self-sovereign identity } \\
\text { system that allows people to own } \\
\text { their identity. }\end{array}$ \\
\hline$R 3^{3}$ & $\begin{array}{l}\text { United } \\
\text { Kingdom }\end{array}$ & National & Private & $\begin{array}{l}\text { Production } \\
\text { Level -Large } \\
\text { Scale Impl. }\end{array}$ & B2B Solutions & $\begin{array}{l}\text { R3 is an enterprise software firm } \\
\text { developing Corda, a distributed } \\
\text { ledger platform designed } \\
\text { specifically for financial services. }\end{array}$ \\
\hline Guardtime $^{4}$ & Estonia & National & Private & $\begin{array}{l}\text { Ongoing - } \\
\text { Large Scale } \\
\text { Impl. }\end{array}$ & Health & $\begin{array}{l}\text { Guardtime is a technology platform } \\
\text { called KSI that allows to tackle hard } \\
\text { problems in security, supply chain, } \\
\text { compliance and networking. }\end{array}$ \\
\hline $\begin{array}{l}\text { Cambridge } \\
\text { Blockchain }^{5}\end{array}$ & Luxembourg & National & Private & $\begin{array}{l}\text { Ongoing - } \\
\text { Large Scale }\end{array}$ & elD & $\begin{array}{l}\text { Cambridge Blockchain's distributed } \\
\text { architecture resolves the competing }\end{array}$ \\
\hline
\end{tabular}

\footnotetext{
${ }^{1}$ https://newsbreak.edu.mt/2018/03/05/thousands-of-maltese-students-to-get-their-certificates-on-blockchain/

${ }^{2}$ https://www.ethnews.com/uport-announces-zug-digital-ethereum-id-pilot

${ }^{3}$ https://en.wikipedia.org/wiki/R3 (company)

${ }^{4}$ https://guardtime.com/blog/increasing-healthcare-security-with-Blockchain-technology

${ }^{5}$ http://blue-dun.com/2018/01/02/digital-identities-cambridge-blockchain/
} 


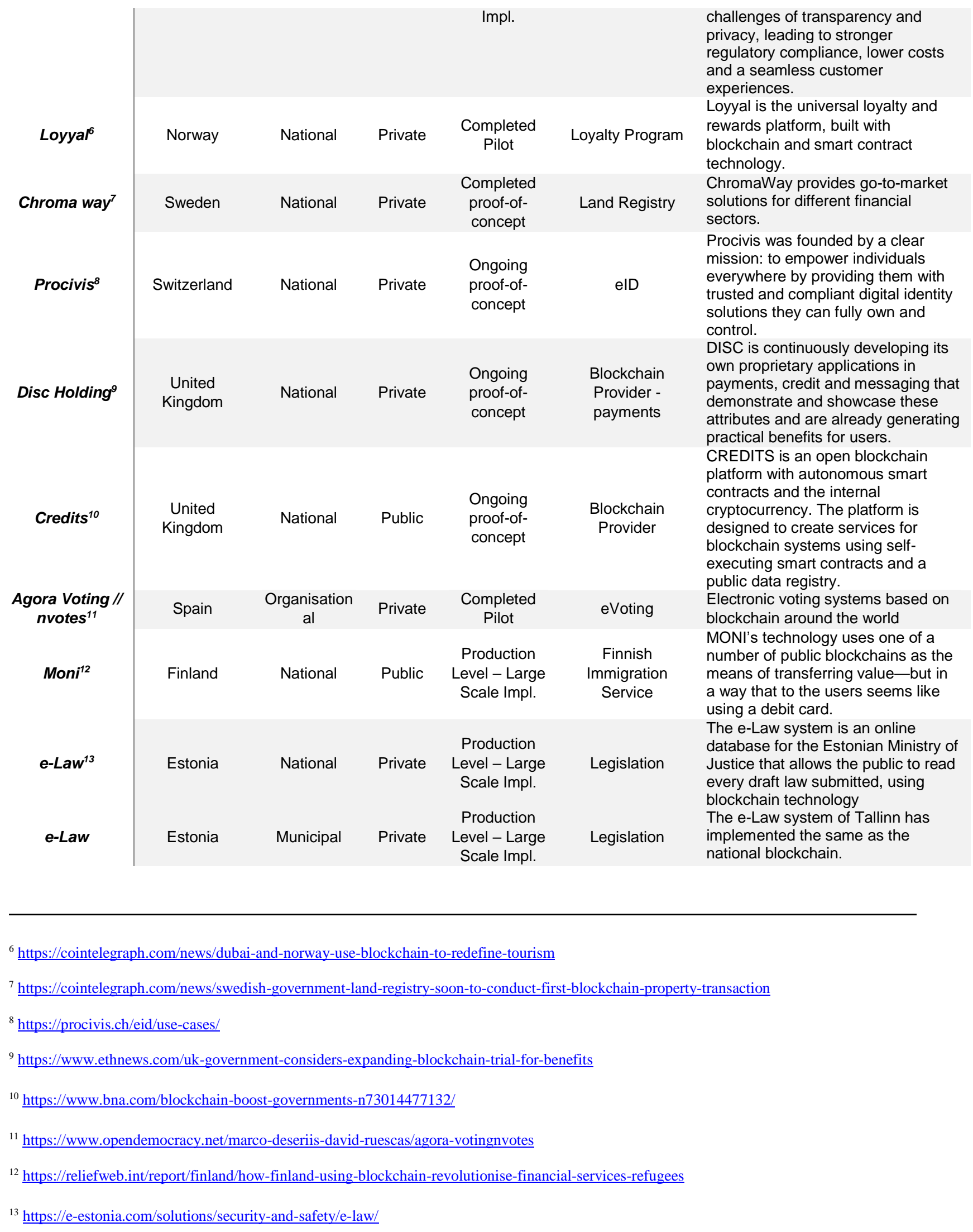

